\title{
Research on the Factors Affecting the Brain Drain of SMEs and Its Countermeasures
}

\author{
Weihong Li \\ Fuzhou University of International Studies and Trade \\ Fuzhou, China 350200
}

\begin{abstract}
SMEs, with their innovative and flexible advantages, play an irreplaceable role in large-scale enterprises in today's market economy. However, the management of SMEs is still lagging to a certain degree, restricting their own development. This paper analyzes the factors affecting the brain drain of SMEs and explores the strategies for SMEs to retain talents, thus improving the brain drain of employees.
\end{abstract}

Keywords—SMEs; brain drain; countermeasures

\section{INTRODUCTION}

With the advent of the new economic era, among the important factors in the development of SMEs, the importance of human resources has exceeded all other resources such as funds. How to retain talents in the fierce market competition may become a real competitive advantage for SMEs. It is one of the most important tasks for the development of SMEs through various effective measures to attract outstanding talents. It is also the most important issue faced by human resources.

\section{FACTORS AFFECTING THE BRAIN DRAIN OF SMES}

\section{A. Nepotism Causes Talents' Loss of Confidence in the Company}

A major problem for SMEs in talent governance is their family-style management, and senior leaders like to use talents according to their personal preferences and their own close relationships. People they appreciate will be given important positions, but to those they hate, No matter how qualified they are, there is no position. Up to $43 \%$ of the positions is held by family members and appreciated individuals, which makes the personnel relationship of SMEs affectionate, vulgar and complicated. Such a group of "family members" often makes the senior leaders exclude the external personnel and the talented people have no chance to be appointed. They lack recognition and lose confidence in SMEs, thus leading to the resignation in SMEs to seek a good personal development space. Even if SMEs are aware of this problem and realize that the importance of talents for the development of SMEs and begins to introduce talents, the core positions of SMEs have been occupied by family members, and the introduced talents will feel that they can't achieve more in this situation and environment and lose confidence, then they will leave.

\section{B. The Salary System and Welfare Protection Are Unreasonable}

The unequal pay for internal and external employees of SMEs makes the talented person thinks that the labor and the rewards he receives are not treated equally and that his ability is not recognized. The opaqueness of SMEs' payrolls makes employees not aware of the reasons for their low or high wages. Those who pay less will think that they are not valued by their superiors and have no statue in SMEs. Employees work overtime without overtime pay, which not only infringes on the employees' own interests, but also reduces the enthusiasm of employees for work, and also causes employees to complain about the company. These directly lead to the resignation of employees.

Unreasonable social security is also one of the reasons for resignation. SMEs regard this part of expenditure as an additional cost of corporate profits and are reluctant to participate in social security activities. This kind of behavior that ignores the interests of employees and the long-term development of the company only by considering their own interests and short-term benefits leads to the lack of security of the employees of the company, causing the loss of talents.

\section{Talents Question Their Development Space}

In today's society, people are increasingly pursuing the release and realization of self-worth. This is especially true for talented people. Interviewees focus not only on money but on the prospects for job development. SMEs have neglected this point and still use a set of fixed methods and rules that SMEs already have. Some are conducive to work efficiency, while others make office procedures cumbersome, complicated and boring. The talents are suffocating when they repeatedly observe these articles every day, which seriously affects the vitality them and makes them unable to see the potential advantages of the company. SMEs have not given employees the opportunity and space for development, so that their talents can't be displayed. Talents think that their own growth and personal value can't be realized, and they can't see their own life value and the direction and goal of their efforts. They are depressed, and they question the development prospects and space of the company. Finally, they are disheartened and choose to leave the company for better development. 


\section{Lack of Employee Training}

Since China's SMEs are still at the initial stage of development, the training costs of SMEs are relatively high, but most companies want training to get the maximum return and achieve the least amount of money invested. SMEs are no exception, but in the case of high costs and short-term benefits, SMEs believe that employee training is a waste of money and a waste of time; even if the cost is low, after the employee training, they have improved their existing comprehensive ability level, their own value, and the talents with more employment choice opportunities to change jobs, so SMEs should also bear the losses and risks caused by resignation. Therefore, employee training is not often carried out. These directly lead to the lack of employee training. However, as far as employees are concerned, today's ideas, knowledge, and technology are changing rapidly, and training becomes a necessary step to keep up with the pace of society and improve themselves. Without employee training, employees will think that their knowledge, ability and status are degraded; they can't keep up with the times; they lose their advantage in the competition of the same industry; they can't integrate into the enterprise better. After a long time, employees will seek further development in better SMEs.

\section{E. Management Is Extensive and the Job Classification Is Not Clear}

SMEs have led to extensive management of enterprises because of their cronyism. In addition, the reasons for the extensive management are: the lack of long-term development plan for enterprise management and it is highly unstable, which is not conducive to the needs of long-term development; the management tends to be superficial, so that the cost input and the benefits obtained cannot be directly proportional, and the enterprise competition has not been substantially improved. Lack of rigorous attitude, unable to establish prestige, staff work is relatively loose. Unreasonable interpersonal relationships constrain the skilled talents and make the job classification unclear. Most of the positions in enterprises are occupied by their relatives, even if he has a mediocre qualification and low performance level, the enterprises cannot use the talented person because of the relationship; the work of each department is crossed, the position becomes less clear, and some people have nothing to do, some People have too many things and overlap with others. This not only caused the loss of work, but also psychologically affected a large number of employees, and there were extremely serious imbalances in the mind of talents, resulting in brain drain.

\section{COUNTERMEASURES FOR SMES TO RETAIN TALENTS}

\section{A. Breaking Through the Boundaries of Employing People and Improving the Confidence of Talents In Enterprises}

SMEs must insist on using talents, break through the boundaries of employing people, and break the situation of employing people. Establishing SMEs is to earn profits, and the profits are created by people, so there is no need to use relatives. The leaders of SMEs should not take the personal they like as the criterion, and use those who are obedient and close with them; they should take "qualification" as the criterion, break through their own psychology boundaries and think about the development of enterprises, they should open up personal feelings, choose those who understand problems from new perspectives and dealing with new methods, those who are good at independent thinking, dare to abandon the rigid system to open up new situations. SMEs want to be big, they should not only to maintain the enthusiasm of their family members, but also to enhance the enthusiasm of outstanding talents, so the talents of SMEs will feel that they are not excluded and restricted in their own businesses, and their own efforts have also received the rewards they deserve. They will change their views on SMEs, and they will have full confidence in the enterprises and will not resign. It is a big gain for both employees and SMEs.

\section{B. Rationalizing Salary System and Welfare Protection}

Employees are one of the important factors in the development of SMEs. Putting employees in the first place when thinking, and being people-oriented, rationalized remuneration system is an embodiment manifestation. For the development of SMEs, they need have high-quality talents. For attracting and retaining talents, the attractiveness of competitiveness and the power of competitiveness are enormous. Based on the important role of remuneration, SMEs need to establish and manage a remuneration system, such as equal pay for equal work between internal and external employees, so that employees feel fair; salary calculation and work performance are combined, so that employees know where the salary is obtained, let them aware of compensation; give appropriate compensation for overtime work to increase employee motivation.

SMEs must correctly understand the benefits of employee welfare protection for the long-term development of enterprises. It cannot be considered as an additional expenditure, but a long-term investment in enterprises. Employees are the wealth of the company, and the welfare protection is a sense of security for the company, so they will work seriously and develop themselves stably in the company. It not only creates profits for enterprises, improves development efficiency, but also reduces the resignation of personnel.

\section{Using Talents and Visions to Dispel Talents' Questions About Development Space}

In order to dispel the doubts about the development space of SMEs, they ask the talents to stay in the company. The leaders of SMEs need to guide the capable people in their own enterprises to work together for the future of the enterprise and build the long-term development direction and goals of the enterprise, and communicate between the two parties effectively to makes it a shared vision and career for both the company and its employees, and allows talent to see their development space. For example, breaking the stereotypes and letting talents see the potential advantages, development direction and goals of SMEs to make the talent work more actively and have more confidence in the enterprise. Managers at all levels of SMEs need to 
understand the characteristics and abilities of talents, as well as their expectations and goals for work, to provide them with opportunities and development space, so that these capable people can realize their potential and talents, so that they can regard their job as career. The enterprise makes the gap between the target vector of the talent and the target vector of the enterprise to be smallest, so that the individual's behavior can be directed toward the enterprise's goal, which makes employees have stronger cohesiveness and a common vision, and strive to accomplish the corporate goal.

\section{Increasing Employee Training}

Some SMEs even stipulate that corporate leaders have the responsibility to train lower-level employees, and whether the leaders have the ability to train lower-level employees is an important factor of examining the ability of the leaders. This shows that increasing employee training is a must for the company. SMEs should establish the concept that "training is investment" and the conviction that "risk can be prevented". Employee training is added to the company's work process, so that employees are always challenged and always have the enthusiasm to improve ability. In this way, they can learn new knowledge, improve their comprehensive ability; improve existing skills, stimulate creativity and ability, and SMEs can continue to grow and develop. SMEs should have a planned talent training system, strengthen training management, and select training courses in a targeted manner to form a reasonable and sound training process. Through strong employee training to find talents, cultivate talents, stimulate talents and retain talents.

\section{E. Fine Management, Dividing Reasonable Positions}

The most urgent task for SMEs is to discard extensive management, commit to the development of fine management, and eliminate the phenomenon of cronyism. Fine management is to carry out long-term planning and development of enterprise management, makes the enterprises have focuses and stabilize their business operations; make the management in-depth and in place, and make cost and efficiency directly proportional to improve their competitive advantage; emphasis on indexing, quantification and precision to establish a prestige and enhance employees' enthusiasm for work. Divide positions reasonably, consider the requirements of different departments and positions, determine the division of department, reduce the overlap of work, reduce the unevenness and overlap of the labor; according to the ability of different talents and the requirements of different positions, select talented people to appropriate position, let the talents play their own strengths, instead of selecting incompetent and incompetent personnel, avoid the vacancy of positions to maximize employee labor results and improve internal competitiveness and work efficiency.

\section{CONCLUSION}

With the improvement of the economic environment, SMEs have considerable development opportunities, which also make the competition rapidly intensified, and talents have become the key to grasping opportunities and competitiveness for SMEs. If SMEs have a place in the environment where enterprises are established and increase their competitive advantages, they must attract and retain talents. In order to attract and retain talents, they must give them space for development, good working environment and reasonable treatment. They should always update the concept, keep up with the pace of the times, attract outstanding talents, create development opportunities, create a bright future for SMEs, and work together for the future of SMEs.

\section{REFERENCES}

[1] Xu Qian, Yue Lei, Jiang Daokui. Research on Early Warning Mechanism of Brain Drain in High-tech Enterprises[J]. Science and Technology Management Research 2015, v.35; No.337(15): 127-130. (in Chinese)

[2] Yang Congjie, Dong Xiaochen. Research on Early Warning Management of Brain Drain Crisis in Enterprises - Based on NonLanguage Communication Perspective[J]. Economic Issues, 2016(8):83-86. (in Chinese)

[3] Yang Hao, Liu Jiawei. Research on the Relationship between Best Human Resource Management Practice and Enterprise Performance[J]. Research Management, 2015(S1): 149-149. (in Chinese) 